\title{
Da favela para o mundo: articulações entre o local e o global no funk brasileiro ${ }^{1}$
}

Debora Costa de Faria²

O funk nacional tem-se mostrado como um importante movimento cultural especialmente entre as camadas mais jovens da população brasileira. Forte o suficiente, para arrebatar audiências em todo o território, e, para além dele, encontrar entusiastas em alguns países estrangeiros que enxergam no gênero uma grande inventividade. A despeito dessa considerável adesão, ele tem enfrentado, desde o seu surgimento, nos subúrbios do Rio de Janeiro, certa rejeição de alguns setores da sociedade brasileira, prontamente justificada entre outras razões, pelo conteúdo de suas letras, a sensualidade dos corpos daqueles que se dispõem a dançá-lo e, por sua presumida conexão com o crime organizado. Este artigo propõe pensar o modo pelo qual o funk brasileiro, seus produtores, adeptos e a indústria da cultura e do entretenimento, têm lidado com essa ambivalência, na qual ora o gênero é julgado como um problema a ser enfrentado pelos órgãos públicos (especialmente os de repressão) e está envolto pelo preconceito e pela desconfiança, ora é visto como uma representação potente e legítima da juventude, em grande parte localizada nas periferias dos centros urbanos do país. Para tal, é importante que seja retomada brevemente a história do funk, assentada em uma revisão bibliográfica que contemple sua chegada aos subúrbios do Rio de Janeiro. Posteriormente, será necessário rever os caminhos tomados por ele desde os primeiros anos e que o levaram a tomar novas configurações em outros lugares dentro e fora do

\footnotetext{
${ }^{1} \mathrm{O}$ título tem como inspiração o mote usado pela cantora de funk Valesca Popozuda. E este artigo é baseado na dissertação "O local e o global no funk brasilero e no kuduro angolano".

${ }^{2}$ Mestre em Ciências Sociais pela Universidade Federal de São Paulo.
}

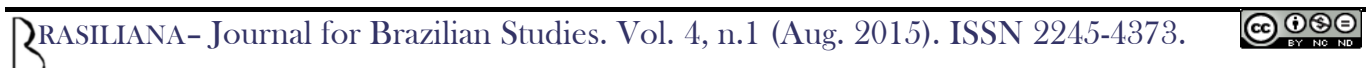


Brasil. Considerando que essa trajetória não possa ser entendida de forma linear, será preciso indicar os problemas enfrentados pelo gênero, seus produtores e admiradores, barreiras que por um lado reforçam preconceitos e estigmas, mas, por outro, não os impedem de ultrapassar os limites a eles impostos.

\section{De como o funk tornou-se carioca (e brasileiro)}

O funk, como é sabido e, enfatizado por alguns de seus apreciadores ${ }^{3}$, não teve seu surgimento em terras brasileiras, é resultado de uma série de experimentações e fusões pelas quais a música negra norte-americana tem passado desde os anos de 1930. Transformações não apenas capazes de gerá-lo, no final da década de 1960, como também a outros gêneros de substancial importância para a história da música, rhythm and blues, soul e rock'n'roll, são alguns deles. Assim como acontece com os gêneros musicais, funk, antes considerado um termo depreciativo, por referir-se ao mau cheiro exalado pelos corpos, é ressignificado e torna-se, por sua importância, ícone do orgulho negro, um símbolo que ultrapassa os limites musicais ao adjetivar, a partir de então, positivamente, as vestimentas, o comportamento social ou ainda os lugares com os quais seus simpatizantes podiam se identificar (Vianna, 1987; Herschmann, 2000).

Por aqui, o funk chega a partir da iniciativa e dos anseios de produtores, DJs, radialistas, interessados e amantes da música em trazer as vibrações do gênero norteamericano para as festas e bailes que tomavam lugar nos clubes do Grande Rio de

\footnotetext{
${ }^{3}$ São recorrentes, no senso comum ou ainda entre os iniciados em música, as tentativas de se fazer distinções entre o funk desenvolvido nos Estados Unidos e que tem como um dos grandes representantes o músico James Brown, e a versão nacional do gênero. Essas diferenciações, que podem ter bases musicais ou geracionais, geralmente elevam o primeiro e, por consequência, acabam por depreciar o segundo.
} 
Janeiro", sendo Ademir Lemos e Big Boy, considerados dois de seus precursores e mais importantes incentivadores. Nesse sentido, o funk foi tornando-se carioca a partir dos anos 1970 com o surgimento dos chamados "Bailes da Pesada", em um movimento no qual foram criadas também as equipes de som, responsáveis pela animação dos eventos que podiam reunir em torno de 5 a 10 mil pessoas, constituindo-se assim, amplos deslocamentos naquelas cidades, pois, essas equipes, atraíam um público fiel, onde quer que se apresentassem; algumas delas, como a Furacão 2000, estão em atividade até os dias de hoje.

À época, e, pelo menos, até a metade dos anos de 1980, as músicas tocadas naqueles ambientes eram além do próprio funk, o soul, o rock e o pop. Apesar dessa variedade de sonoridades - para se ter uma ideia, alguns produtores flertaram até mesmo com a disco music -, nesse período, de modo geral, a música negra norteamericana, o soul, o funk e mais tarde, o hip hop despontaram como os gêneros preferidos entre os participantes das festas. Este último, um amplo movimento cultural, - conhecido por reunir música, dança, intervenções gráficas nos muros e metrôs das cidades, além da conscientização política -, é fruto da mistura de influências americanas, como o funk e, afro-caribenhas, como a atmosfera trazida pelos sound systems jamaicanos. O hip hop era, naquele momento, encabeçado por jovens negros e latinos, moradores de zonas periféricas de grandes cidades dos Estados Unidos, sendo o bairro do Bronx, em Nova York, considerado seu grande centro criador. O rap, sua vertente musical, transfigura-se, deste modo, na manifestação a partir da qual era possível a seus criadores denunciarem as desigualdades que os cercavam. Ele é também elemento dos

\footnotetext{
${ }^{4} \mathrm{Já}$ em meados dos anos de 1970, os bailes - alguns deles promovidos por Ademir Lemos e Big Boy -, começam a fazer parte do circuito de outras cidades do país, Brasília, São Paulo, Porto Alegre, Minas Gerais e Salvador são algumas delas. Esta última caracterizou-se por eventos nos quais o apelo à consciência e à valorização da cultura negra destacava-se. Caso semelhante, de tentativas de politização e militância nos bailes, também aconteceram no Rio de Janeiro, com equipes de som como a Soul Grand Prix (Vianna, 1987; Assef, 2003; Sá, 2007).
}

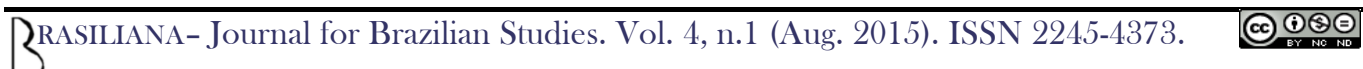


mais relevantes para a constituição da variedade de influências formadoras daquilo que será conhecido como funk carioca. Isso decorre do fato dele ter sido acidentalmente misturado pelo DJ e produtor Afrika Bambaata - considerado, ao lado de Kool Herc e Grandmaster Flash, um dos grandes nomes associados ao movimento nova yorkino -, à música eletrônica da banda alemã Kraftwerk. Essa mistura, por sua vez, gerou o electro e o miamibass, base musical sobre a qual irão ser criadas as primeiras músicas de funk no Brasil, no final da década de 1980 (Vianna, 1987; Connell E Gibson, 2003; Essinger, 2005; Sá, 2007).

Ao contrário do que se poderia imaginar, a adesão a essas sonoridades, não deve ser entendida a partir da concepção que ronda os mais ferozes críticos da globalização e que poderiam enxergar a sua apreciação nos bailes e nas estações de rádio daquela década como uma possível imposição ou colonização cultural (Vianna, 1987; Sá, 2007). Essa ideia não se sustenta, pois, o funk carioca é um gênero que toma suas influências e desenvolve-se para além do circuito mais tradicional de distribuição e comercialização de música, desenrolando-se, portanto, à margem da grande indústria fonográfica e do entretenimento. Por esses motivos, para o funk no Brasil, foi imperativo, desde muito cedo, criar métodos próprios de produção e circulação, além de modos particulares de lidar com os sons estrangeiros.

O funk foi se consolidando como uma expressão popular e juvenil no Brasil a partir de negociações e misturas criativas de referentes e códigos locais e globais. Não por acaso, Hermano Vianna (1987), em consonância com os modernistas brasileiros, entende essas habilidades como antropofágicas, já que a cultura musical estrangeira era deglutida, apropriada e transformada de modo que ganhasse significação naquele contexto. Nesse sentido, são famosas as histórias dos modos alternativos pelos quais desde o seu surgimento, os DJs e promotores de festas encontravam para adquirir novos discos e novas músicas - algumas delas, mal conhecidas até mesmo entre os norte- 
americanos. Para se ter uma ideia, além de excursões relâmpagos, feitas pelos próprios DJs, para garimpar as novidades sonoras, especialmente nas cidades de Nova York e Miami, havia toda uma rede de contatos estabelecidos entre funcionários de agências de turismo ou companhias aéreas, além de amigos que traziam do exterior os discos que permitiam aos produtores dos bailes inseri-los em seus eventos e, viabilizavam o acirramento da competição entre os DJs e as equipes, a partir da promessa de que sua festa seria a melhor, pois, teria mais sons exclusivos, dentre todas as existentes. Para que tal expectativa fosse cumprida, valia até dificultar a identificação dos discos com o intuito de assegurar que algumas das músicas de sucesso fossem associadas a equipes e festas específicas ${ }^{5}$. Outro indício de que esse repertório estrangeiro não era consumido de maneira passiva pelos admiradores do gênero, pode ser demonstrado com base na prática de inserção criativa de elementos e questões cotidianas, além de sensibilidades locais àquelas músicas importadas, como acontecia no caso das melôs e do processo de homofonia que as envolvia. Este recurso, largamente utilizado durante aquele período, permitia aos frequentadores dos bailes tomar posse das sonoridades ao acrescentar a elas letras em português que se tinham pouca ou nenhuma relação com seu real significado em inglês, muito significava para seus autores ${ }^{6}$, configurando-se, deste modo, as primeiras adaptações e reconfigurações do gênero que irá ganhar novas formas alguns anos mais tarde (Vianna, 1987; Herschmann, 2000; Sá, 2007).

Assim, neste contexto de apropriações criativas, o funk e mais tarde, o próprio o miami bass são tomados e ressignificados pelos cariocas a partir dos anos de 1970.

\footnotetext{
${ }^{5}$ Práticas semelhantes foram frequentes também na constituição do reggae na Jamaica.

${ }^{6}$ Havia inclusive concursos nas rádios para renomear ou "batizar" as canções estrangeiras que faziam sucesso nos bailes (Sá, 2007). Cabe notar ainda que esse artifício, comum entre os brasileiros, foi expresso também, por razões semelhantes, tanto nos bailes que agitavam São Paulo, ainda na década de 1960, quanto em canções como a "Melô do Tagarela", considerada um dos primeiros raps brasileiros, embora seja uma versão de "Rappers Delight" do grupo norte-americano Sugarhill Gang (Assef, 2003).
}

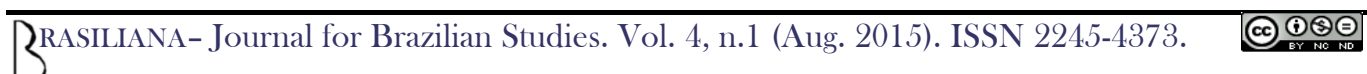


Entretanto, ainda que as primeiras coletâneas das sonoridades adotadas pelas equipes tivessem sido lançadas em meados daquela década e, tenham alcançado um certo sucesso, é nos anos de 1990 que se dá a grande guinada do funk em direção ao abrasileiramento. É nesse período, iniciado com as experimentações e os esforços empreendidos pelo DJ Marlboro para lançar a compilação Funk Brasil, ainda em 1989, que, tanto as produções quanto as letras do gênero começam a ser feitas por artistas brasileiros, não obstante, permanecessem muitas das influências formadas a partir da fusão de referentes locais e globais, com especial destaque para o miami bass base estrangeira sobre a qual os acontecimentos cotidianos e localizados dos jovens cariocas eram manifestados e cantados nos bailes. Nesse caso, segundo o próprio Marlboro argumenta, a escolha pela manutenção e continuidade com a música de Miami, não teria se dado de modo casual, pois, o DJ e produtor acreditava que havia uma aproximação sonora com o samba, familiar aos funkeiros. A conexão com sonoridades afro-brasileiras se estende nos anos posteriores com a adoção do atabaque eletrônico e a geração do "pancadão", em meados da década de 1990 (Vianna, 2003), confirmando, assim, a vocação do gênero de combinar e reinterpretar sonoridades e temas. Em continuidade com essa ideia, Simone Sá explicita algumas das habilidades importantes dos músicos naquele momento e que até os dias de hoje permanecem fundamentais para as composições das músicas do gênero:

[...] Ainda que as letras sejam escritas em português, retratando cada vez mais as questões do cotidiano das favelas e bairros de periferia e com forte apelo ao território ou à comunidade a sonoridade pode

\footnotetext{
${ }^{7}$ Marlboro é, além disso, considerado importante por elevar o papel do DJ dentro das equipes de som, pois, é um dos primeiros a tocar de frente para o público, em um momento no qual as equipes eram os elementos mais valorizados dos bailes, já que era especialmente a elas e não aos DJs e MCs que os frequentadores conferiam fidelidade (Assef, 2003; Sá E Miranda, 2013).
} 
remeter a inúmeras e inusitadas referências - da Tarantella à Madonna, de Prodigy a Gilberto Gil, da vanguarda do Krafwerk - uma das importantes e recorrentes citações do funk - a trilhas de filmes famosos. Além disto, um mesmo material pode ser utilizado em canções diferentes, em versões e remixes ou em novas composições aproximando o funk das práticas de outros gêneros dentro da música eletrônica e confirmando a importância das noções de reapropriação e circularidade para a compreensão do processo. (Sá, 2007:11)

Nesse encadeamento contínuo e interminável, entre referentes locais e globais e do qual a música não é a única a participar - embora seja o elemento privilegiado dessa análise , a globalização deixa de ser algo impalpável, algo que está para além dos indivíduos que nessa conjuntura ganham agência. Esse é um contexto no qual o conceito de local, tem se alargado e sua conexão com o global se potencializado, especialmente nas últimas décadas por conta do rápido desenvolvimento das comunicações e dos transportes, elementos facilitadores da circulação de ideias e de pessoas, e que podem favorecer o estabelecimento de identificações formadas não apenas dentro das fronteiras territoriais. Do mesmo modo, a globalização, não é entendida de maneira essencializada, como uma força capaz apenas de homogeneizar as manifestações culturais de todo o mundo. Como argumenta Stuart Hall,

Este "local", não deve, naturalmente, ser confundido com velhas identidades, firmemente enraizadas em localidades bem definidas. Em vez disso, ele atua no interior da lógica da globalização. Entretanto, parece improvável que a globalização vá simplesmente destruir as identidades nacionais. É mais provável que ela vá produzir, 
simultaneamente, novas identidades "globais" e novas identificações “locais". (Hall, 2006: 78)

Nessa conjuntura de aproximação de distâncias e intensificação das possibilidades de criação e interação (especialmente por meio de recursos eletrônicos e comunicacionais), a inter-relação que o funk brasileiro, não apenas em suas sonoridades, tem continuamente demonstrado entre os elementos locais e globais demonstra que o gênero e seus produtores têm se beneficiado intensamente de tais facilitadores ao longo de sua constituição, apropriando-se de fluxos culturais advindos de diversas fontes, mas, também os transformando de forma a particularizá-los e devolvê-los para o Brasil e o mundo com características próprias. Como prova disso, as manifestações desenvolvidas a partir dele continuam esse processo, como acontece no caso do passinho, formado a partir de uma profusão de estilos de dança e, de sua vertente ostentação, da qual falaremos adiante, cuja estética visual e de composição lírica, assemelha-se a movimentos de música internacionais.

Antes disso, nos anos 2000, esses processos persistiam e marcavam um outro momento bastante significativo para o funk nacional. Embora os anos 1990, já tivessem assistido a uma aproximação entre a música produzida nas comunidades e os jovens da classe média carioca - cuja frequência nos bailes era cada vez mais comum -, além de um aumento da aparição de artistas do gênero em programas populares como o Xuxa Park ${ }^{8}$, da TV Globo e a criação de outros especialmente dedicados ao gênero, como o Furacão 2000, produzido pela equipe de som de mesmo nome, é, no início do século XXI

\footnotetext{
${ }^{8}$ O programa exibido aos sábados e apresentado por Xuxa Meneguel, ganhou, em 1994, um quadro dedicado a uma parada de sucessos na qual eram destacados artistas de funk convidados pelo DJ Marlboro (Essinger, 1994). Essa abertura de portas da apresentadora para o gênero lhe rendeu o título de embaixadora ou ainda madrinha do funk.
} 
que são configurados novos rumos e espaços para este gênero ${ }^{9}$. Se ainda nos anos de 1970, os "Bailes da Pesada" tiveram que mudar de lugar, saindo da casa de shows Canecão ${ }^{10}$, na zona Sul do Rio de Janeiro, em direção aos subúrbios e favelas nos quais se afirmou, na década de 2000, o funk produzido no Brasil passa a ocupar de modo considerável palcos em ambientes antes cerceados à sua introdução: casas noturnas localizadas em bairros de classe média e alta de grandes cidades como Rio de Janeiro e São Paulo, telenovelas, propagandas de televisão, desfiles de moda, festivais nacionais e internacionais de música. Além disso, nessa altura o próprio funk remodela seus temas e sonoridades, pois, é nesse contexto que são evidenciadas as músicas de conteúdo sensual, ou "putaria" (Sá, 2007), especialmente aquelas cantadas por mulheres, e, cujas letras que variam entre o duplo sentido e a narração explícita de desejos e cenas eróticas, são consideradas como um modo contestatório de problematizar os papéis (social e sexual) da mulher, de modo que o palco e a música tornam-se plataformas para a liberação feminina (Sneed, 2008). Ainda nesse período, vêm à cena dois documentários cujas abordagens recaem sobre as peculiaridades do gênero: Sou feia, mas tô na moda (2005), de Denise Garcia e Favela on Blast (2008), dirigido pelo brasileiro Leandro HBL e o DJ norte-americano Diplo (que assina o filme como Wesley Pentz). É aí também que o funk nacional alcança os circuitos internacionais, a partir das mãos dos DJs brasileiros, convidados a se apresentar fora do país, ou, dos apreciadores estrangeiros que passam a incluir as músicas do gênero em seus sets e compilações de música eletrônica. O funk

\footnotetext{
${ }^{9} \mathrm{Na}$ década de 1990, também podem ser observadas aproximações entre o gênero e artistas conhecidos de pop e MPB, como Fernanda Abreu e Lulu Santos.

${ }^{10}$ A história está bastante documentada na bibliografia sobre o funk no Brasil (Vianna, 1987; Herschmann, 2000; Essinger, 2005; Sá, 2007). Os "Bailes da Pesada" inicialmente tomavam lugar (e faziam muito sucesso) na casa de shows Canecão até o momento em que a direção, interessada em sediar uma apresentação de Roberto Carlos, achou por bem voltar-se para a MPB. Interessante notar que alguns anos depois o cantor, em seu habitual especial de final de ano, convidou ao palco MC Leozinho para cantar um dos hits de 2006, "Se ela dança, eu danço". E, além disso, em 2012, Roberto Carlos surge com sua própria versão do gênero, "Furdúncio", um dos temas da novela global Salve Jorge.
} 
brasileiro também alcança os circuitos internacionais pelas vozes de seus MCs e de interessados no exterior, com quem a aproximação se dá a partir da adaptação de suas batidas em seus trabalhos, continuando, assim, uma trajetória de apropriações criativas, ressignificações, bricolagens e uso de elementos preexistentes que inspiram a criação de novas músicas, renovam e reaviavam as articulações entre local e global, centro e periferia.

\section{Funk brasileiro: entre o encantamento e o estigma}

Mas, engana-se quem acredita que essa trajetória do funk no Brasil tenha se dado sem quaisquer obstáculos que tentassem impedir sua manifestação. Neste sentido, essas histórias de sucesso do gênero dentro e fora do país não podem, nem devem, ser entendidas de modo evolutivo ou de maneira que se possa argumentar que esses caminhos tenham se dado sem algumas dificuldades. Embora este pareça ser um momento de destaque e de aderência ao gênero, com suas sonoridades sendo inseridas e apreendidas de modo favorável pelos meios musicais e de comunicação, ao longo de sua história, o funk produzido no Brasil tem oscilado entre momentos de retração e abertura; sua trajetória tem sido envolta por preconceitos, hostilidades e repressões, acusações e questionamentos com relação à sua legitimidade enquanto um movimento cultural.

Um episódio fundamental para entender a ambivalência pela qual o gênero tem sido considerado no decorrer dos anos, é aquele que na conturbada década 1990 ficou conhecido como "arrastão". O ano era 1992 e o local a praia de Ipanema, uma das regiões mais abastadas da cidade do Rio de Janeiro. A movimentação em massa de jovens, em sua maioria negros, vindos de algumas das regiões mais desassistidas da cidade, naquelas areias eternizadas pela famosa canção de Tom Jobim e Vinícius de 
Moraes, causou tumulto e repercussões dentro e fora do Brasil, e, além disso, gerou reações negativas que ajudaram a criar e dar visibilidade ao personagem do funkeiro como uma figura nociva e perigosa, uma ameaça que de alguma forma feria o universo simbólico da sociedade (ARRUDA Et Al., 2010, HERSCHMANN E FREIRE FILHO, 2003). Essas repercussões, ainda hoje ecoam no imaginário social, como demonstram os trechos ${ }^{11}$ abaixo:

[...] Uma parede humana avança sobre os banhistas, pavor e insegurança. Sem que se saiba de onde, começa uma grande confusão. O pânico toma conta da praia. As pessoas correm em todas as direções. São mulheres, crianças, pessoas desesperadas à procura de um lugar seguro. A violência aumenta quando gangues rivais se encontram [...] Dois policiais, apenas dois, chegam até a areia. Eles estão armados mas parecem não saber o que fazer com tanta confusão e correria.

$\mathrm{Na}$ verdade isso foi provocado pelo governador da época. Que criou uma linha de ônibus que ligava de forma direta a favela de Vigário Geral a praia do Arpoador. Na época os bailes funks de corredor ${ }^{12}$ estavam em moda. As chamadas gangs do funk resolveram sair do underground dos bairros perifericos e promover o seu showzinho particular na zona sul da cidade. Além de brigarem, aproveitavam a brecha para roubar aqueles que aproveitavam o Domingo para curtir uma praia $[\mathrm{sic}]$.

\footnotetext{
${ }^{11}$ Os dois trechos foram retirados do Youtube, site no qual usuários comuns podem disponibilizar vídeos e músicas. Ver: "Arrastão na Praia de Ipanema, 1992." Disponível em: https:/www.youtube.com/watch?v=5lgX1ph7DoI. Último acesso em: 08/04/2014.

${ }^{12}$ Bailes nos quais galeras rivais se encontravam para externar (não raro, a partir da violência física) suas rivalidades.
} 
Mais de vinte anos separam as transcrições acima. A primeira, é proveniente de um telejornal da época, o Jornal Nacional, transmitido pela TV Globo no mesmo dia do incidente, 18 de outubro de 1992. As cenas que ilustram a reportagem, especialmente aquelas da confusão nas areias, estão distantes, sendo necessária sua interpretação pela voz do narrador combinada a recursos televisivos que deem sentido a elas. As outras imagens que se seguem a essas, em outras emissoras, estão mais próximas: banhistas dando seus depoimentos, rapazes sendo presos, ônibus lotados na volta para casa; ademais, em outra reportagem, a localização de moradia daqueles jovens, "adolescentes do subúrbio e da Baixada Fluminense", é destacada. Fizeram parte daquele momento ainda, explicações e soluções propostas pelas autoridades para que incidentes como aquele não mais ocorressem. Tudo isso somado, ajudou a dar dramaticidade e, sobretudo, visibilidade, aos acontecimentos. O segundo trecho da citação é um comentário (segundo a plataforma, publicado há pelo menos dois anos), entre as dezenas disponíveis, na mesma página na qual reportagem mencionada pode ser acessada. Aqui as imagens parecem estar na memória (ainda que algumas vezes televisiva) do evento. Mais de vinte anos se passaram, mas, por meio desses trechos pode-se perceber que o imaginário negativo produzido em torno daquele acontecimento tem sido reiterado ao longo deste período - embora comentários que tentem matizar o incidente também estejam presentes. Tempo suficiente para que houvesse uma retomada e uma expansão do funk para além dos subúrbios cariocas, entretanto - como sugere a leitura de algumas postagens preconceituosas que acompanham os vídeos -, insuficiente para desfazer a associação entre o gênero musical, a violência e a criminalidade.

Embora materialmente pouco tenha sido perdido - Nilo Batista, secretário da Justiça e da Polícia Civil da época teria afirmado que apenas uma toalha e um par de

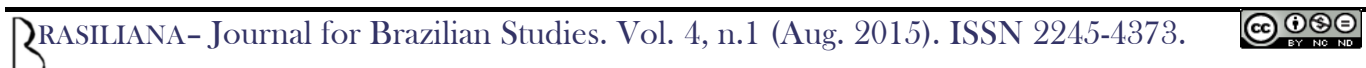


chinelos tinham sido roubados, e, uma reportagem no jornal da TV Bandeirantes afirmou não haver queixas significativas de banhistas nas delegacias de polícia da região -, o que sobrou deste episódio foram, sobretudo, os danos simbólicos. Para os habituais frequentadores da praia, faltou a capacidade de lidar com a presença do "outro" que parecia invadir seu território, enquanto que para os funkeiros, ficou reservado o estigma e uma série de associações negativas que, para alguns, permanecem até os dias de hoje. Como pontuam Arruda et alli:

Não era o funqueiro que estava sendo criminalizado, mas o jovem pobre, negro e favelado. O funqueiro era sua objetivação no momento. Esses jovens, multidão em movimento agressivo para os padrões locais, surgem como algo inquietante. $\mathrm{O}$ fenômeno de confronto de galeras na praia, território sagrado da classe média da Zona Sul do Rio de Janeiro, é algo inusitado, de modo geral - e inaceitável para a população que ocupa esse espaço. Na verdade, então, o que se está traduzindo é esta invasão de territórios por "bárbaros", estranhos no ninho, que vêm perturbar a paz ensolarada do paraíso urbano. No caso, as imagens já estavam lá, e se reacomodariam, ganhando nova denominação. A denominação dada foi o arrastão, cujo personagem principal logo seria identificado ao funqueiro. (Arruda et al., 2010: 415)

Por outro lado, foi essa confusão que trouxe à tona e tornou visível ao grande público o fenômeno do funk carioca, até então desconhecido por grande parte da imprensa (Vianna, 1987; Herschmann, 2000; Herschmann e Freire Filho, 2003). Esta não foi, entretanto, a única circunstância na qual o gênero ganhou destaque nos meios de comunicação e, em alguns casos, essa evidência coincide com momentos de abertura nos 
quais o interesse pela sua música, o estilo de vida e as práticas nas quais está inserido são sobrepostos às polêmicas que o envolvem. Dito de outro modo, é como se no momento em que transcendem as comunidades pobres cariocas - ou seja, os espaços urbanos físicos e simbólicos aos quais o funk "deveria" pertencer -, o gênero e seus entusiastas estivessem a querer alterar e ocupar espaços aos quais não pertenciam, provocando preocupações e reações adversas das autoridades e da população que tinham (e ainda hoje têm) dificuldades de compreendê-lo; mas, de modo contraditório, tais campanhas difamatórias e proibitivas podem ter se tornado um meio pelo qual o gênero e os aspectos culturais que o envolvem tenham se expandido, ampliando, deste modo, suas geografias de produção, atuação e consumo.

Assim, Herschmann (2000) indica o modo como entre 1993 e 1995, iniciou-se uma "segunda campanha de criminalização", no mesmo momento no qual os jovens de classe média "descobrem" e começam a frequentar os bailes de comunidade, passando a dividir o mesmo espaço físico - e sonoro - com os moradores locais. Esse "flerte" é interessante também por revelar o indício de um primeiro encantamento de apreciadores de fora das favelas e dos subúrbios pelo funk produzido no Rio de Janeiro. Anos mais tarde, Paul Sneed (2008) enxergaria nesses encontros, a formação de uma espécie de comunidade unificada, formada em torno da música e da dança e, para além disso, capaz de transcender alguns binarismos históricos e conjunturais (negros e brancos, pobres e ricos, moradores e não moradores das comunidades) considerando o baile, ainda que provisoriamente, o momento no qual diferenças e hierarquias criadas fora dele seriam apaziguadas. Mais do que isso, o baile e as práticas geradas em torno dele, produziriam um descentramento em relação às relações habituais e se converteriam em modos de valoração positiva das pessoas pobres, da geografia do lugar onde vivem, de suas manifestações culturais, por fim, seria o lugar e a circunstância na 
qual - diferente do que comumente acontece na vida cotidiana -, os moradores poderiam expressar sua força e seu poder.

Mas essa visão utópica não era comum a todos e a aproximação daqueles jovens era entendida por alguns grupos da sociedade brasileira como inoportuna e indesejável justamente porque nesse mesmo período aparecem os chamados "raps de contexto" (ou "proibidões") - uma vertente do gênero caracterizada por versões ilegais de músicas, nas quais eram feitas homenagens àqueles associados às facções criminosas -, motivo de alarme para a imprensa, setores das classes médias e as autoridades. Situação parecida com a que foi identificada por Essinger (2005), já no final dos anos de 1990, pois, as músicas, que, de modo geral são acusadas de apologia ao crime e ao tráfico de drogas, levaram alguns de seus autores e intérpretes a serem inquiridos por forças policiais. Essas discussões, porém, passam ao largo do encantamento que o gênero tem conquistado ao longo dos últimos anos, especialmente no exterior. Para se ter uma ideia, um dos temas (ou alvos) recorrentes nessa vertente musical dos proibidões eram os delatores (Essinger, 2005) e as consequências que eles teriam que encarar caso passassem alguma informação à polícia ou a rivais. Mas, nos anos 2000 Tejo, Black Alien e Speed também criaram sua própria versão de funk, com o já sugestivo nome "Quem que caguetou". Sucesso como trilha sonora do filme "O Invasor"13 (2001) de Beto Brant, a música atravessou os limites brasileiros para embalar a propaganda da montadora de carros japonesa Nissan ${ }^{14}$ e tornar-se hit em alguns países da Europa, com direito a ganhar diversos remixes e distinção por ser considerada uma das melhores músicas de

\footnotetext{
${ }^{13}$ Baseado no livro homônimo de Marçal Aquino, o filme, que se passa em São Paulo, além de alguns prêmios conquistados, também se tornou célebre pelas marcantes atuações de Paulo Miklos, um dos integrantes da banda Titãs e do rapper Sabotage, morto em 2003.

${ }^{14}$ Ver: "Nissan X trail by Fréderic Planchon". Disponível em: https://www.youtube.com/watch?v=us75DwsuSP0. Último acesso: 08/04/2015.
} 
comercial de $2003^{15}$. Relevante aqui é notar que Fréderic Planchon, diretor da peça publicitária, um francês entusiasta do funk brasileiro, ao ser questionado sobre o real significado da letra da música, revelou não se importar com seu conteúdo já que o seu maior interesse estava assentado em sua sonoridade.

Outro ponto a ser destacado com relação aos estigmas carregados pelo funk é que eles reiteram a associação entre cor da pele, origem social, localização de moradia criminalidade e, para alguns, (mau) gosto musical. Além disso, podem provocar medidas restritivas e repressoras - que ora limitam, ora confinam as festas às comunidades e favelas - como tem ocorrido no Rio de Janeiro ao longo dos anos. Podem provocar ainda discussões sobre juventude, segregação socioespacial, o direito à cidade e à mobilidade urbana, como aconteceu em São Paulo com fenômenos recentes como os "rolezinhos" e os "fluxos" também conhecidos como "pancadões de rua". O primeiro ocupou os noticiários brasileiros entre o final do ano de 2013 e os primeiros meses de 2014 e foi caracterizado pelos encontros marcados via redes sociais, entre jovens moradores da periferia que lotavam os shoppings da cidade mas, por sua quantidade e seu suposto perigo, preocuparam os lojistas a ponto de buscaram na justiça modos de inibir e reprimir (muitas vezes de forma violenta) a livre circulação dos adolescentes que não raro usavam como trilha sonora de seus encontros músicas de funk ${ }^{16}$. Este, quando saído de equipamentos potentes acoplados aos carros estacionados nas ruas, como nas festas ao ar livre, também se torna um problema, gera reclamações dos moradores e assim como ocorreu com os rolezinhos, provoca tentativas de mediação, regulação e interdição por parte do poder público e dos setores mais conservadores da sociedade.

\footnotetext{
${ }^{15}$ Ver: "Quem que cagoetou?", de Tejo, Black Alien e Speedy, é hit na Europa. Disponível em: http://www1.folha.uol.com.br/fsp/ilustrad/fq0512200324.htm. Último acesso: 07/2014.

${ }^{16}$ Para mais análises desse fenômeno consultar: "Rolezinho no shopping: aproximação etnográfica e política" (2014), de Alexandre Barbosa Pereira e "Rolezinhos: sociabilidades juvenis, discriminações e segregação urbana" (2014), de José Gomes da Silva e Darlene Fróes da Silva.
} 
Apesar desse tipo de reação ao gênero não constituir-se como uma novidade, pois ressalvas que tendem a descaracterizá-lo como uma manifestação cultural relevante ou ainda que o consideram como uma música (de) pobre, e, portanto, associada indistintamente à criminalidade, o acompanham como vimos demonstrando, desde o seu surgimento. Com relação aos "rolezinhos" e aos "fluxos", tais descréditos e desconfianças coincidem com a ascensão da vertente "ostentação" do funk brasileiro. Criada em São Paulo e na Baixada Santista as batidas conhecidas do funk carioca ganham novos tons ao ter adicionadas a elas letras nas quais o consumo de roupas, óculos, carros e bebidas de marcas famosas (e importadas), além do acesso a outros bens como propriedades no litoral e camarotes em casas noturnas, são supervalorizados. Embora não seja uma unanimidade, a ironia a ser sublinhada nesses casos, é que esta vertente, por afastar-se da temática da violência, tem sido entendida como uma espécie "funk do bem" (Barbosa, 2014), tornando-a em certa medida, mais palatável - assim como o "funk melody", versão mais romântica do gênero -, ao grande público e nos meios de comunicação brasileiros.

\section{Guimê: "ostentação fora do normal"17"}

"MC Guimê leva o funk ostentação ao topo do mainstream com a faixa 'País do Futebol' na abertura da novela 'G3R4ÇÃO BR4S1L'”. Com este título inicia-se a reportagem do Portal Vírgula, com um dos nomes mais conhecidos daquela vertente ${ }^{18}$. Com uma trajetória comum à de outros ídolos do gênero, a de um rapaz humilde que inicia a

\footnotetext{
${ }^{17}$ Em referência à música dos MCs Daleste e Léo da Baixada.

${ }^{18}$ Disponível em: http://virgula.uol.com.br/musica/pop/mc-guime-leva-o-funk-ostentacao-ao-topo-do-mainstreamcom-faixa-pais-do-futebol-na-abertura-da-novela-g3r4cao-br4s11/\#img=1\&galleryId=140564. Acesso em: $24 / 03 / 2015$
} 
produção e a divulgação de seus videoclipes e apresentações de modo modesto nas periferias da cidade onde vive - Osasco, região metropolitana de São Paulo -, e com auxílio da internet, nos últimos tempos, MC Guimê se transformou em um dos expoentes mais importantes do funk ostentação, sendo destaque por ter inclusa sua música na abertura de uma novela da rede Globo, patrocinado por marca de energético e de chicletes, ter mais de 200 milhões de visualizações no seu canal do Youtube, ser capa da revista Veja, possuir uma marca com produtos próprios e por ter o aval de outros ídolos jovens como o jogador de futebol Neymar e o rapper Emicida com quem divide a música mencionada, desfazendo as barreiras postas entre o funk e o hip hop (rap) brasileiros. Mas, nem com todos esses méritos, Guimê, um dos maiores ídolos do funk, escapa a essa oscilação da qual estamos nos referindo. Em reportagem publicada no jornal norte-americano Los Angeles Times, o funk ostentação encarnado a partir de sua figura ganha destaque. Publicado em abril de 2014, com o título "In Brazil, music for the flaunters and the wanters" ${ }^{19 "}$ (em tradução livre: "No Brasil, música para os que ostentam e os que desejam"), o artigo descreve por um lado o alcance que a vertente ostentação tem em clubes de elite e nas camadas sociais mais abastadas, às quais as narrativas que valorizam a posse de carros, joias e produtos de luxo deveriam fazer mais sentido. Por outro, incute a ideia de que haja uma oposição entre o que é cantado e a realidade socioeconômica dos funkeiros e de parte de seus fãs. Além disso, questiona a validade de serem compostas letras de músicas que façam elogio ao consumo em uma sociedade como a brasileira na qual a pobreza e, consequentemente a desigualdade ainda alcançam níveis alarmantes. Uma sociedade, entretanto, na qual apenas recentemente o poder de compra de uma fração das classes populares tem sido elevado. Nesse sentido, se, por um lado, as músicas do funkeiro seriam comparáveis àquelas

\footnotetext{
${ }^{19}$ Disponível em: http://www.latimes.com/world/mexico-americas/la-fg-c1-ff-brazil-bling-rap-20140404mstory.html\#ixzz2yKMMRiUz\&page=1. Acesso em: 04/2014.
} 
produzidas pelos rappers norte-americanos a partir da estética "bling $20 "$, na qual o conteúdo contestador do início do rap esgota-se em favor da valorização da temática do consumo, por outro, elas se afastariam, assim como outras canções dessa mesma vertente, de funks como o "Rap da Felicidade", no qual uma série de reivindicações estão inseridas.

Esse tipo de análise advém também de grupos que esperam um posicionamento político mais crítico das populações desassistidas dos centros urbanos, entendendo o hip hop, com sua força contestadora como um modelo ideal a ser seguido (Pereira, 2014). Entretanto, embora este movimento tenha sido fundamental na constituição do funk carioca (não por acaso as primeiras composições brasileiras do gênero levam o nome de rap, como no caso dos Raps da Felicidade, do Silva e das Armas), nos anos de sua consolidação, o movimento funk foi considerado, de modo geral, um opositor ao movimento hip hop. Dois gêneros criados a partir de uma mesma fonte musical, mas que ao longo de sua inserção no país foram colocados em oposição por meio de discursos e narrativas baseados na ideia de que o primeiro estaria a serviço da diversão e, portanto, do esvaziamento político, enquanto o segundo trabalharia em prol da denúncia e do combate dos males sociais.

Essas oposições revelam, mesmo que de maneira implícita, a ideia de que a um grupo social seria legítimo criar apenas um determinado tipo de música, baseado na experiência real de seus praticantes. No sentido oposto, os argumentos de Alexandre Barbosa Pereira (2014) apontam para o importante papel que a imaginação e a fantasia têm na composição das músicas e dos vídeos do funk ostentação. Sobretudo porque se baseia na ideia de Arjun Appadurai (1996), de que os meios de comunicação são

\footnotetext{
20، Bling" refere-se ao som das caixas registradoras, denotando nesse sentido, uma valorização do consumo. Outra característica deste estilo é o uso excessivo de joias e a ostentação de carros de luxo e roupas de marcas famosas nos videoclipes dos músicos norte-americanos.
}

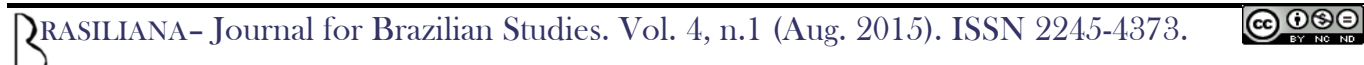


elementos fundamentais para compor essas duas dimensões, na contemporaneidade. Mais do que isso, o funk ostentação e suas imagens demonstram que as afinidades e conexões podem se assentar para além dos limites do bairro, da cidade e do país de origem, transformando em imagens o sonho de uma vida melhor e ascensão social dentro de um contexto de exclusão. Sobre as críticas, MC Guime pontua:

Antes de nos criticarem, eles têm que criticar o canal de TV e todas as propagandas porque nós crescemos vendo isso, e como posso negar que sempre quis ter um bom carro, se cresci vendo que todas aquelas pessoas respeitadas na sociedade têm bons carros? [E continua] Todo dia, na TV, a família rica está feliz e a família pobre está triste. Como eu não vou querer o que a eles é permitido ter?

De maneira geral, a circulação e a visibilidade de Guimê que alcança espaços no mercado da música e do entretenimento, nos clubes noturnos de classe media, no rádio e na televisão revelam algumas questões nas quais não apenas o músico, mas o gênero como um todo está envolvido, como pontuam João Freire Filho e Micael Herschmann (2003), entre a “demonização" e a "glamourização", entre a crítica e o fascínio.

Em sua análise sobre as relações entre o funk e os meios de comunicação brasileiros, Freire e Herschmann afinam o conceito de "pânico moral" trazido pela sociologia britânica, ao propor que a imprensa não é responsável apenas por produzir e disseminar bodes expiatórios, ou seja, figuras, situações ou comportamentos que de algum modo, ferem ou questionam o universo simbólico ou a ordem estabelecida de uma sociedade. Nesse sentido, por sua heterogeneidade e multiplicidade de interesses, os media, juntos à indústria cultural, deixariam de ser apenas criadores e legitimadores de rótulos negativos no momento em que abrem brechas para o que consideram ser 
"vozes discrepantes", se manifestem, para que sua cultura e estilo de vida sejam expressos, valorizados e difundidos. Essa situação seria ampliada com o avanço da tecnologia, por isso, não é estranho que embora enfrente todos os obstáculos observados, ao longo dos últimos anos, possa ser indicada uma aderência ao funk brasileiro - ou, pelo menos, de algumas de suas vertentes -, pelos meios de comunicação que inserem suas sonoridades e seus artistas em programas populares de televisão, peças publicitárias e nas trilhas sonoras de novelas. Além disso, o gênero está cada vez mais presente nas diversas regiões do país e tem encontrado certo reconhecimento de suas produções, passando a ser respeitado e elogiado, por suas inovações sonoras, por músicos brasileiros consagrados, assim como por produtores estrangeiros. O funk brasileiro parece estar, nesse sentido, em uma espécie de pêndulo, no qual é entendido como um assunto a ser resolvido pela segurança pública, ora é identificado como uma manifestação cultural vibrante.

\section{Do funk para o (Brasil e o) mundo ${ }^{21}$}

Ainda que seja colocado no centro de diversas polêmicas, sugerimos que o funk produzido no Brasil tem conseguido se destacar e circular para além das comunidades onde é criado de, pelo menos, três maneiras. Na primeira delas, são os próprios funkeiros que circulam e através de suas performances alcançam o "asfalto", outras cidades do país, as pistas de dança da classe média e do mundo, como acontece com os DJs Marlboro e Sanny Pitbull, além de músicos como Tati Quebra Barraco, Deize Tigrona, Valesca Popozuda e MC Catra. O segundo seria aquele no qual o funk brasileiro conquista admiradores de gêneros consagrados pela crítica e pela audiência,

\footnotetext{
${ }^{21}$ Subtítulo inspirado no lema da Liga do Funk, organização criada em São Paulo, no ano de 2012 e que tem entre seus objetivos apoiar e promover o funk no Estado.
} 
como no caso de Gilberto Gil e Caetano Veloso, que em seu último disco, Abraçaço (2012), abriu espaço para o gênero com o seu "Funk Melódico". E, o último movimento, seria aquele no qual a música ultrapassa os espaços das comunidades, do estado do Rio de Janeiro e do país, alcança e passa a ser produzido pela classe média brasileira como no caso dos curitibanos do Bonde do Rolê, ou, por produtores e artistas internacionais, como a cantora anglo-cingalesa M.I.A., o DJ norte-americano Diplo e o produtor alemão Daniel Haaksmann.

Os modos de circulação propostos demonstram, em certa medida, as dinâmicas envolvidas no funk brasileiro e que operam desde o momento de sua criação, passando por seu desenvolvimento enquanto um gênero nacional $e$, finalmente, em sua capacidade de expansão para além das comunidades nas quais foi ressignificado. Seu dinamismo é demonstrado, portanto, no momento em que é apropriado pelos cariocas nos anos de 1970 e no desenrolar das décadas seguintes, nas quais se espalha para outras cidades brasileiras, onde vai se firmando como uma das maiores manifestações culturais da juventude até os dias de hoje. Entretanto, isso não significa que a adesão ao gênero seja exclusiva, visto que nas casas noturnas dedicadas a apresentações de funk, ele divide espaço com o pagode, o axé e o hip hop. O funk é plástico também a partir das estratégias de seus artistas que criam versões mais leves para músicas mais polêmicas (o contrário também seria verdadeiro), retirando ou colocando palavras e versos, dependendo da audiência para a qual vão se apresentar.

De qualquer modo, essa expansão evidencia-se na medida em que o funk tornase um gênero apreciado em diversas regiões do país, mas, assumindo peculiaridades, temas e afinidades locais como no caso do funk ostentação, produzido na capital da cidade de São Paulo e na Baixada Santista ou ainda nas produções dos curitibanos do Bonde do Rolê. O gênero é dinâmico, ao incorporar às suas sonoridades, novas e diversas influências ou ter suas batidas e temas incorporados por outros gêneros e 
estilos musicais brasileiros como o pagode e o sertanejo universitário ou, mais recentemente, o arrocha, música apreciada no nordeste do país, especialmente no estado da Bahia, e que com o cantor Neto LX, ganha nova roupagem e temas bastante semelhantes àqueles caros aos do funk ostentação, sendo a menção, nas letras ou nos vídeos, a marcas famosas de roupas e o uso de cordões de ouro, os elementos que sustentam o chamado "arrocha ostentação".

Em tempos de maior acessibilidade aos meios digitais de produção de música e à internet, plataformas virtuais de compartilhamento de música e vídeo como o Youtube, tornam-se meios fundamentais através dos quais vídeos feitos com celulares ou grandes produções são difundidos virtualmente para qualquer pessoa interessada ao redor do mundo. Essas facilidades, aliadas ao barateamento de equipamentos, não apontam apenas para a possibilidade de criação e divulgação de sonoridades, mas, também tornam viáveis a produção imagética que ajuda a difundir tanto as músicas quanto as narrativas visuais e os estilos de vida que são parte delas. Tais possibilidades acabam por gerar, concomitantemente, profissionais especializados na produção de vídeos para acompanhar as músicas, como ocorre com Kondzila, diretor responsável por alguns dos vídeos mais assistidos do funk ostentação (Pereira, 2014). Essa não é, entretanto, uma novidade no mundo do funk no Brasil, pois, há anos pesquisas apontam o poder de mobilização do gênero, além da possibilidade dele se constituir em uma alternativa entre o emprego formal e a associação com o crime (Souto, 1997), viabilizando, portanto, a alguns dos jovens que trabalham nesse meio uma mudança considerável nas suas vidas e de suas famílias.

No que se refere ao interesse de músicos, produtores e DJs estrangeiros, ele advém, em grande parte, da intenção de mostrar ao mundo as "descobertas" sonoras encontradas em países da periferia, numa dinâmica que se por um lado se assemelha àquela produzida pela world music nos anos de 1980, por outro, dela se diferencia no 
momento em que valoriza a mistura de sonoridades locais e globais, abrindo mão da autenticidade musical assentada em noções de pureza e tradição. Nesse caso, esses apreciadores, colocam-se como mediadores que ora "apresentam" as músicas do gênero ao público externo quando atuam em casas de shows, clubes noturnos, em programas de rádio, festivais, ou, ainda, por meio de compilações e coletâneas, ora incorporam as batidas do funk brasileiro em criações próprias. Os "globalistas 22" M.I.A., Diplo e Daniel Haasksman - a quem é creditado o modo como o gênero é denominado fora do país, "baile funk" - são três dos nomes mais conhecidos dessa tendência que, ajudou o funk alcançar o mundo e a inspirar novas apropriações em países como Estados Unidos, Alemanha, Itália e até mesmo Rússia e Lituânia, como aponta reportagem do jornal O $\mathrm{Globo}^{23}$.

O funk brasileiro, porém, não é o único gênero musical ao qual a estética periférica encanta produtores estrangeiros que o inserem nos mercados globais de música. Diante de um contexto contemporâneo no qual as culturas marginalizadas parecem estar cada vez mais em evidência, gêneros como a cumbia argentina, o kwaito sul-africano e o kuduro angolano, acabam por se tornar parte de uma tendência que tem ganhado várias denominações, world beat, world music 2.0, global guettotech, global bass, tropical bass, nu whirled e, apesar das controvérsias que a cercam (Bailey, 2010) tem seguido em busca de sonoridades vibrantes e que não raro, têm em comum, o fato de serem criadas em zonas desassistidas de grandes centros urbanos por jovens que fazem uso extensivo de recursos e equipamentos tecnológicos e aparatos eletrônicos e digitais. Esses, propiciam a produção de musicalidades e imagens próprias, sem que para isso

\footnotetext{
${ }^{22}$ Termo indicado pelo DJ e jornalista Camilo Rocha (2010) para identificar os interessados em buscar novas sonoridades.

${ }^{23}$ Ver: "O mundo é um baile funk". Disponível em: http://oglobo.globo.com/cultura/o-mundo-um-baile-funk8858467. Acesso em: 07/2015.
}

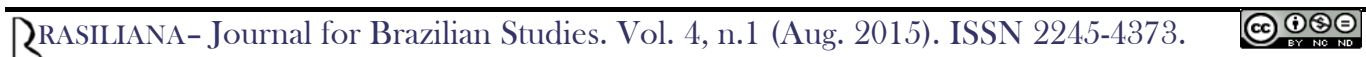


haja a intermediação de grandes gravadoras ou de meios de comunicação tradicionais. Músicas criadas em contextos urbanos, quase sempre precários, mas que nem por isso deixam de criar e difundir estilos de vida particulares, de pessoas que mesclam, sem medo, referências locais e globais.

\section{Considerações finais}

O funk inicialmente conhecido como carioca tem se revelado como uma das expressões culturais mais interessantes e controversas no cenário da música brasileira. Descendente direto daqueles que nos anos de 1970 ficaram conhecidos como "Bailes da pesada" promovidos em clubes do Grande Rio, por jovens entusiastas da música negra norteamericana, há muito que o gênero não se restringe apenas a essa região, mas, espalha-se de maneira vertiginosa, como uma manifestação musical, especialmente produzida e apreciada entre a população jovem das periferias de grandes cidades, fenômeno que por um lado permite a agregação de especificidades locais ao funk e por outro, torna possível entendê-lo como funk brasileiro. Entretanto, na mesma medida em que cresce o interesse em torno das práticas que o rodeiam e que não se limitam apenas aos setores menos abastados da população brasileira, crescem também as ressalvas com relação ao gênero. Ainda assim, conquista audiências fora das favelas e comunidades, além de entusiastas - ainda que de maneira mais fluida e transitória -, nas pistas de dança internacionais, apesar de sua condição periférica. Entretanto, seria um erro considerar essa condição como dada. Alguns dos exemplos trazidos aqui, demonstram os constantes movimentos que ora aproximam, ora distanciam o funk brasileiro (ou uma parte dele), das indústrias da música e do entretenimento. Os exemplos trazidos aqui demonstram que apesar de tudo, o funk permanece. Permanece no som alto que faz vibrar os vidros das casas, apesar das reclamações de seus moradores, nos fluxos, ainda 
que sejam combatidos pela polícia, nos bailes, onde as pessoas cantam, dançam e se divertem, nos vídeos da internet que alcançam centenas ou milhões de visualizações. Por fim, permanece constituindo narrativas, estilos de vida juvenis e agências que de outra forma lhes seriam negados.

\section{Referências}

Arruda, Angela, Jamur, Marilena, Melicio, Thiago, \& Barroso, Felipe. De pivete a funqueiro: genealogia de uma alteridade. Cadernos de Pesquisa, 40(140), 407-425. 2010.

Assef, Cláudia. Todo DJ já sambou: a história do disc-jóquei no Brasil. São Paulo: Conrad Editora do Brasil, 2003.

Appadurai, Arjun. Modernity at large: Cultural dimensions of globalization. University of Minnesota Press, 1996.

Bailey, Thomas B. "What in the world is 'global ghettotech': radical riddims or neoexotica? http://vagueterrain.net/content/2010/03/whatworld-global-ghettotech-radicalriddims-or-neo-exotica, 2010.

Caio, Manoel. S. Cumbia villera, Kuduro e Technobrega: repercussões e repertórios dinâmicos das cenas musicais. Comunicação no XXIV Congresso da Associação Latinoamericana de sociologia, 2013.

Dayrell, Juarez. Juventude, grupos de estilo e identidade. Belo Horizonte: Educação em revista, pp. 25-39, 1999.

. O rap e o funk na socialização da juventude. In: Educação e Pesquisa, pp. 117-136, São Paulo, v.28, n.1, p. 117-136, 2002.

Faria, Debora C. O local e o global no funk brasileiro e no kuduro angolano. Dissertação de mestrado. Guarulhos: Escola de Filosofia, Letras e Ciências Humanas. Guarulhos, 2014.

Essinger, Sílvio. Batidão: uma história do funk. Rio de Janeiro: Record, 2005.

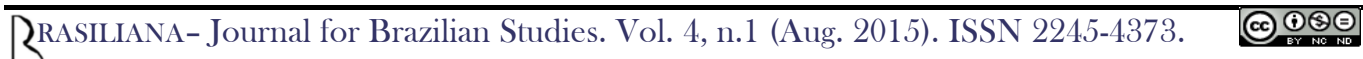


Freire, João; Herschmann, Micael. Funk carioca: entre a condenação e a aclamação na mídia. Eco-Pós. http://revistas.ufrj.br/index.php/eco_pos/article/view/1133.

Hall, Stuart. A questão da identidade cultural. Textos didáticos. São Paulo, SP: IFHC/Unicamp, 1998.

. A identidade cultural na pós-modernidade. Rio de Janeiro: DP\&A Editora, 2006.

Herschmann, Micael. O funk e o hip hop invadem a cena. Rio de Janeiro: Editora UFRJ, 2000.

Pereira, Alexandre. B. Funk ostentação em São Paulo: imaginação, consumo e novas tecnologias da informação e da comunicação. In: Revista de estudos culturais. São Paulo 2014.

Rocha, Camilo. Globalistas' buscam sons periféricos. In: http://www1.folha.uol.com.br/folha/ilustrada/ult90u358180.shtml, 2007 SÁ, Simone. Funk carioca: música eletrônica popular brasileira? Brasília: E-Compós, 2007.

Sá, Simone; Miranda, Gabriela. Brazilian Popular Music Economy Aspects: The Baile Funk Circuit. In: IASPM Journal (Journal of the International Association for the Study of Popular music), v. 3, pp. 9-18, 2013.

Sneed, Paul. Favela utopias: The Bailes Funk in Rio's crisis of social exclusion and violence. In: Latin America Research Review. v. 43, n. 2, pp. 57-79, 2008.

Souto, Jane. Os outros lados do funk carioca. In: Vianna, Hermano (org.). Galeras cariocas. Rio de Janeiro: Editora UFRJ, 1997.

Vianna, Hermano. O baile funk carioca: festas e estilos de vida metropolitanos. Dissertação de mestrado. Museu Nacional, Universidade Federal do Rio de Janeiro, 1987

- Do samba ao funk: música e globalização no Rio de Janeiro no século XX. Apresentação. Casa da América, Madrid, 2003. 